\title{
An instructional method for increasing originality'
}

\author{
RESEARCH AND DEIELOPMENT CENTER FOR LEARNING AND RE-EDUCATION, UNIVERSITY OF WISCONSIN
}

College $S$ s were instructed to imagine themselves within a particular situation and to list uses for a given object within that situation. These Ss produced a larger total number of ideas, a larger number of original (unique) ideas, a larger proportion of original-to-total ideas, a larger number of "good" ideas, and a greater proportion of good-to-total ideas than $S s$ not receiving the Situations instructions.

Several investigators in the general areas of originality, creativity, and problem solving have suggested that original "ideas" and novel problem solutions are typically produced by the combination of previously unrelated ideas (e.g., Mednick, 1962; Staats \& Staats, 1963 , p. 236). A direct implication is that pretraining or instructional conditions which require $S$ to combine familiar ideas will result in the production of original responses. The present report describes an instructional technique for stimulating Ss to combine previously unrelated ideas or associations. Generally, S was asked to imagine himself in a particular situation (e.g., on a picnic) and to list as many uses as he could for a particular object (e.g., a hanger) within that situation. It was expected that imagery or associations related to, e.g., the picnic occurring contiguously with associations related to, e.g., the hanger would result in a larger number of original combinations of ideas. For comparison purposes, data are presented from earlier (unpublished) studies in which Ss were instructed to either (a) list as many uses as they could for the object (neutral instructions) or (b) list uses for the object which were both original and practical.

\section{Method}

Each of 12 college Ss listed uses for three objects (a tire, a hanger, and a screwdriver), one object in each of three "situations" (a picnic, a classroom, and a party). Ten min. were allowed for each of his three problems. The instructions, printed at the top of each of three 25-line legal-sized response sheets in a booklet, read, "Imagine you are (on a picnic/at a party in a friend's home/in a classroom). List as many uses as you can for a (hanger/tire/screwdriver) within that situation."
The particular combinations of each of the three situations with each of the three objects, and the presentation orders of these combinations, were determined by the rows of two 3 by 3 Graeco-Latin squares which contained all six presentation orders of the three situations (Latin letters) and all six presentation orders of the three objects (Greek letters). Each situation occurred equally often with each object, and each object and each situation occurred equally often in each ordinal position. There were two Ss per row.

The $30 \mathrm{Ss}$ from the earlier study also listed "as many uses as they could" in 10-min. sessions for the same three objects, a tire, a hanger, and a screwdriver. The two instructional conditions of present interest were (1) "Don't worry about being original nor about being practical" (neutral instructions, Condition $\mathrm{N}$ ) and (2) "Try to be original and try to be practical (Condition OP).

Seven dependent measures were available: (1) Mean number of responses given per 10-min. session. (2) Mean level of originality (uniqueness) of each use, as rated on 9-point scales (1-9) by two judges. (3) Mean level of practicality (usefulness), as rated on 9-point scales. (4) Mean number of original responses (responses with ratings of " 6 " or higher on the originality scale by both judges). (5) Mean percent original responses (original/total). (6) Mean number of "good" ideas per 10-min. session. (A "good" idea is defined as an idea which is both original and practical. Hence ideas with ratings of " 6 " or above on both the originality and practicality scales by both judges were counted as "good.") (7) Mean percent "good" ideas (good/ total).

\section{Results}

Data for the Situations condition and conditions $\mathrm{N}$ and OP for all seven dependent measures are summarized in Table 1. Under the Situations instructions, Ss produced significantly more uses than under instructions to "be original and be practical" (Condition OP, $t=4.55, \mathrm{df}=40 ; \mathrm{p}<.01)^{2}$ and more uses than under the neutral instructions (Condition $N$ ) although not significantly more $(t=1.54, d f=40, p<.20)$. The Ss' average

Table 1. A Summary of Experimental Data

\begin{tabular}{|c|c|c|c|c|c|c|c|}
\hline Instructions & $\begin{array}{c}\text { Mean Number } \\
\text { Uses Given }\end{array}$ & $\begin{array}{c}\text { Originality } \\
\text { Ratings }\end{array}$ & $\begin{array}{c}\text { Practicality } \\
\text { Ratings }\end{array}$ & $\begin{array}{c}\text { Original Responses } \\
\text { per } 10 \mathrm{~min} .\end{array}$ & $\begin{array}{c}\text { Proportion } \\
\text { Original }\end{array}$ & $\begin{array}{c}\text { "Good" Responses } \\
\text { per } 10 \mathrm{~min} .\end{array}$ & $\begin{array}{l}\text { Proportion } \\
\text { "Good"" }\end{array}$ \\
\hline Situations & 17.06 & 5.71 & 4.76 & 7.47 & $43.71 \%$ & 1.33 & $7.80^{\circ} \%$ \\
\hline $\begin{array}{l}\text { Be Original, } \\
\text { Be Practical }\end{array}$ & 10.20 & 4.67 & 6.12 & 3.47 & $34.02 \%$ & .40 & $3.92 \%$ \\
\hline Neutral & 14.63 & 4.63 & 6.02 & 4.67 & $31.92 \%$ & .57 & $3.88 \%$ \\
\hline
\end{tabular}


level of originality, as rated by judges, was also significantly higher under the Situations instructions than under condition $\mathrm{N}$ or $\mathrm{OP}(\mathrm{ts}=3.49$ and 3.04 , respectively, $d f=40, p<.01$ ). The Ss under the Situations instructions not only gave a greater number of responses rated by both judges as original than Ss in Condition OP $(t=3.01, \mathrm{df}=40, \mathrm{p}<.01)$ or in Condition $\mathrm{N}(t=1.97$, df $=40, p<.10)$, but also produced a higher percentage of original responses (original/total).

In spite of the fact that $S s$ in the Situations condition produced responses which, on the average, were rated as low in "practicality," these Ss still produced significantly more "good" ideas (rated as original and practical by both judges) per 10-min. session than Ss in condition $O P(t=2.72, d f=40, p<.01)$ or condition $\mathrm{N}(\mathrm{t}=2.17, \mathrm{df}=40, \mathrm{p}<.05)$. Also, the percentage of good ideas (good/total) was double that of either condition $\mathrm{N}$ or $\mathrm{OP}$.

\section{Discussion}

The present data show a striking effect upon the production of original combinations of ideas by instructing $S$ to imagine himself in a particular situation and to find uses for a given object within that situation. Compared with Ss given essentially neutral instructions and Ss instructed to be original and practical, Ss receiving the Situations instructions produced a larger total number of ideas, a larger number of original ideas, a larger proportion of original-to-total ideas, a larger number of "good" (original and practical) ideas, and a greater proportion of good-to-total ideas. It seems very likely that this increment in originality resulted from requiring Ss to contiguously view previously unrelated ideas or associations, thus producing new combinations of ideas. The data can thus be taken as support for positions viewing original behavior as emerging primarily from the combination of familiar ideas (Mednick, 1962; Staats \& Staats, 1963).

As a final note, the present technique conceivably could be added to the industry-related methods described by Arnold (1962) for the systematic generation of problem solutions, new products, new uses for products, etc. As with the other techniques described by Arnold (e.g., brainstorming, attribute listing, and various checklist procedures), the present method would result in a myriad of impractical and wila uses for various objects in various situations, but some practical and profitable ideas might also appear.

\section{References}

Arnold, J. E. Useful creative techniques. In S. J. Parnes \& H. F. Harding (Eds.), A source book for creative thinking. New York: Scribner's 1962. Pp. 251-268.

Mednick, S. A. The associative basis of the creative process. Psychol. Rev., 1962, 69, 220-232.

Staats, A. W., \& Staats, Carolyn K. Complex human behavior. New York: Holt, 1963.

\section{Notes}

1. This research was performed pursuant to contract OE 5-10-154 with the United States Office of Education, Department of Health, Education, and Welfare, under the provisions of the Cooperative Research Program. Alice Train assisted with the ratings.

2. All tests are two-tailed.

3. Several of our studies have shown practicality (usefulness), and originality (uniqueness) to be inversely related. 